\title{
Locating Tween Girls
}

\author{
Melanie Kennedy and Natalie Coulter
}

$\cos$

\begin{abstract}
We reflect on the media coverage of Amy "Dolly" Everett's death by suicide to highlight the continued spectacularization of tweenhood as an idealized form of white feminine beauty tied to consumer culture, and one that shores up contradictory notions of the can-do/at-risk girl binary. We consider contemporary tweenhood's continuities with the visibility and concerns of girlhood from the 1990s while questioning what a definition of tweenhood in the age of digital media and beyond the boundaries of whiteness, heteronormativity, able-bodiedness, and the Global North might look like. Calling for a discursive approach to understandings and conceptualizations of tweens, we introduce the eight articles in this special issue that range from media representations of the tween to lived experiences of actual tween girls.
\end{abstract}

Keywords: Amy “Dolly” Everett, consumer culture, liminality, media users, race

As we were writing this introduction, our online news and social media feeds filled up with the image of a tween looking directly at us, smiling: as news circulated globally of the death by suicide of the 14-year-old Australian Amy "Dolly" Everett after she had been bullied online, the photograph accompanying the reports was of Everett in an advert for the Australian hat brand Akubra, taken when she was eight years old. Very few recent images of 14year-old Everett appeared in the coverage.

With only her face and collar visible, the signs of tweenhood are clear; her baby teeth tie her to the cuteness of childhood while the over-sized felt hat is a nod to adult years which, like the hat, she cannot yet fit into. Although she was 14, Everett is crystallized in this image of ideal tweenhood, this moment of liminal girlhood. This ideal tween is white-unambiguously white with blonde curls - with a confident smile, embedded in consumer culture. She is an icon of the nation, bound up, in this case, with the brand identity of Akubra which positions itself as a symbol of nationhood founded on family values and the formation of a national culture. As Sarah Projansky says of the girl star, here Dolly "is a promise of the continued dominance of whiteness" (2014: 54) and the guarantee of the future of the nation. 
Throughout the news coverage of Everett's suicide she is referred to as Dolly. The Daily Mail quotes her father's description of her as “'a perfect little china doll'" (Cleary 2018: n.p.), further defining her as the ideal girl, permanently held in this moment of liminality, a commodity of idealized white beauty. The repeated reoccurence of the photograph of eight-year-old Everett across news outlets and social media, and the close-up nature of the image focusing in on her whiteness and blondness, spectacularize the girl as an example of this pervasive phenomenon of contemporary media explored by Projansky in Spectacular Girls (2014). Here, in this image, we see spectacularization manifesting in ways specific to tweenhood, this particular moment of girlhood. In particular, we see the spectacularizing of her liminality and her embeddedness in consumer culture.

While her image visually communicates notions of Anita Harris's (2004) can-do girl, the circumstances of her death and the debates this generated in the media simultaneously shore up the notion of her having been an atrisk girl, and attach this label to her. Concerns about the ways in which girls navigate the contemporary digital media landscape, manage relationships, perform a socially expected gendered identity, and develop a clear sense of self within this context, are facilitated via this image of eight-year-old blonde white Dolly. (We see critical engagement with these debates in the articles in this special issue.) Projansky argues that "whiteness and ambivalent anxiety (primarily about the relationships among childhood, sexuality, and/or gender) precondition [the girl star's] visibility" (Projansky 2014: 28) in media, and here we have not a film star but a star of advertising, and an accidental star of the news. She is both idealized through her unambiguous whiteness and she is a site of ambivalent anxieties about girls' media use.

The coverage of Everett's death and the discussions that followed, then, remind us of the cultural visibility of tweenhood, and that the subject of the tween - one bound up with deep-rooted assumptions about race, beauty, and consumer culture-is a site onto and through which contemporary social anxieties and debates about vulnerable group members' uses and navigations of new media (newer at least than the platforms and technologies girls studies scholars such as Harris were writing about over a decade ago) get projected. It seems then that the concerns expressed in the 1990s by girlhood advocates such as Mary Pipher (1994) that girls lose their sense of self as they enter adolescence, have continued and indeed become intensified as we move into the late 2010s, and the tween girl—with her contradictory status as both a future-looking symbol of idealized consumption and femininity, and as being vulnerable and in need of protection-has become so 
central to these concerns. Of course, the continued prevalence of the cando/at-risk binary in cultural depictions of girls has been noted by others in the field such as Catherine Driscoll (2002) and, more recently, Tiina Vares and Sue Jackson (2015), but we argue, in this special issue, that such contradictions and binaries of girlhood become amplified in the figure of the tween girl in particular.

In our call for papers, we asked how we might define the pre-adolescent girl in the field of girlhood studies, and what methodologies are required for the study of tweens. In our work, we have called for the tween to be understood as a discursive construction: the tween is

discursively articulated in the synergistic relations of the mediated marketplace, as advertisers, retailers and merchandizers try to cull her as a customer, as the media attempts to define her as an audience and as marketers work to get to know her as a market. (Coulter 2014: 5)

Beyond the consumer marketplace,

tweenhood, as a discursively constructed moment in girlhood, takes its meaning not only from the representations that make up tween popular culture, but also from writing in popular discourses that has attempted to make sense of and define the apparent emergent subject of the tween. (Kennedy in press)

The articles in this issue continue this discursive exploration of the tween, revealing the ways in which our understandings of her come from public service broadcasters' television programs (Godfrey), and through observations of and participation in girls' interactions when watching TV together (Maurer). Understandings come via conversations with girls about their sending of sexts (García-Gómez), from girl-made videos using the dolls of tween culture and disseminated on YouTube (Johnston), and from projects and blogs produced by girls at a technology camp (England and Canella). Understandings also come from nationally-specific literary representations of the tween body and her place in the family (Steffler), and from queer constructions of gender (Byers) and the representation of girls of colour (Whitney) in middle-grade fiction. It is within, through, among, and between these spaces, places, voices, and objects that we find contemporary understandings of the tween. Taken together, they provide a nuanced, sometimes complicated, and fascinating picture of tweenhood today. They suggest both a continuation of our previous definitions of this moment of pre-adolescent girlhood and a disruption of the widely held assumptions we have about this subject.

Importantly, in our search for discursive definitions of the tween, we wanted to include the lived experiences of actual girls, and were pleased that 
so many articles here do just that; they demonstrate the breadth of research being carried out within and outside of girlhood studies that listens to the voices of girls themselves and pays attention to the cultures, objects, and spaces produced by tween girls. While these articles reveal the ways in which girls engage with, negotiate, and resist the framing of the tween as, largely, a white, middle-class, heteronormative subject, there is still much work to be done in the field to explore the representations and lived experiences of tweenhood that does not fit the definition of it as able-bodied and/or Western. There is also much work to be done on tween girls in the Global South.

In the first article, Sarah Godfrey examines tween television programming by the British Broadcasting Corporation aimed at tweens and asks in what ways these textual constructions of tweenhood share a resemblance to (and can be seen to differ from) the US television programming to which attention is more often paid in studies of tween media. She reveals that the British television context produces a distinctive nationally-specific version of tweenhood, arguing that we must pay attention to national discourse when making sense of media constructions of the tween girl. Turning to the television audience, Cynthia Maurer discusses the time she spent with a group of preadolescent friends watching television together in the space of the home, to reflect on the conversations and negotiations of friendshipwhat she calls friendship work- that took place while they talked about television shows. She found that talking about television shows is a central tool in tweens' understandings and negotiations of their peer culture, as well as a space within which to manage their social relationships.

Disrupting straightforward narratives told frequently in debates about young people's use of digital and mobile media, and girls' use in particular, Antonio García-Gómez explores questions of sexual agency in pre-adolescent girls' self-presentation in sexting. Drawing on interviews with British girls, he found that there are contradictory constructions of femininity in their reflective talk about sexting, and tensions between expected hegemonic femininity on the one hand, and agency and empowerment on the other.

Jessica Johnston focuses on American Girl dolls as objects of tween culture and on YouTube videos produced by teenage girls and adult women that feature these dolls in a retrospective reconstruction of their tweenhood years and, in so doing, explores some aspects of the intertextuality of tween culture. This online doll culture prompts us to question our assumptions about the marketplace boundaries of tweenhood, and what these digital spaces allow for in the lived experiences of tweenhood and in the later reconstruction of this time in women's lives. 
Jen England and Robert Canella draw on their experiences as mentors with the Girlhood Remixed Technology Camp to explore how tween girls define themselves as girls in and through media technologies. Using a technofeminist framework, the authors outline the possibilities of giving girls the technical and digital skills to produce content that challenges traditional narratives of girlhood. This piece reminds us of the ways in which research can be an activist practice.

The final three articles explore the discursive constructions of tweens in literature. Michele Byers examines four middle-grade novels. She looks specifically at the ways in which the trans and gender nonconforming tween characters resist gender normativity and use spaces and objects to make their gender identities legible. These characters invite the reader to look with as opposed to at their trans and gender non-conforming selves. These books, as she points out, offer the perspectives of agentic children who do not have to wait until adulthood to live their nonconforming gender identities.

Sarah Whitney reads the middle grade novels of Sherri Winston through the lens of Black Girl Magic. She explores how the novels reclaim an aesthetic of sparkle to create visibility for girls of colour in white postfeminist spaces. Whitney offers us a way of thinking through how girls push back against the narrow framings of tweenness that are embodied by icons such as Everett, that "promise ... the continued dominance of whiteness" as mentioned above.

Margaret Steffler analyses the representation of tween girl hero Thebes Troutman in the adult novel The Flying Troutmans (2008) by Miriam Toews. Thebes is introduced by way of Anne Shirley, the tween hero of the 1908 novel Anne of Green Gables. In this later novel Thebes's skin and body become a site of both subversion of, and transgression away from, the liminality of conventional tweenness, and introduce the possibilities of the tween's role in transgressing the traditional boundaries of families and nations.

\section{Acknowledgments}

We are deeply grateful to Claudia Mitchell for giving us the opportunity to guest edit this special issue. She generously helped us to turn a vague idea that developed over coffee at the International Girls Studies Conference at the University of East Anglia in 2016 into this special issue. Our sincere gratitude also extends to all the contributors who responded to our call for papers with such intelligent and eloquent papers. And, of course, a huge 
thank you must be extended to all the girls who participated in the research described in this issue. We also thank the anonymous reviewers who generously took time to provide careful and thoughtful feedback on the articles. Finally, we wish to thank Ann Smith for her meticulous editing and keen eye for inconsistent argument. Without her guidance, support, and gentle prodding, this special issue would not have been possible.

Natalie Coulter is currently an Assistant Professor at York University in the department of Communication Studies. Her research focuses on girls' studies, critical advertising studies, children's media, and consumer culture. She is currently completing a SSHRC funded research project, The Embodied Tween: Living Girlhood in Global and Digital Spaces. Her book, Tweening the Girl: The Crystallization of the Tween Market, came out in 2014. Natalie has published in the Canadian Journal of Communication, Journal of Children and Media, Popular Communication, and Jeunesse. She is a founding member of the Association for Research on the Cultures of Young People (ARCYP). E-mail: ncoulter@yorku.ca

Melanie Kennedy is a Lecturer in Media and Communication at the University of Leicester where she teaches predominantly on stardom and celebrity culture. Her research is rooted in feminist media and cultural studies, and examines media representations of gendered, age-defined, classed, raced identities (in particular tweens, young female celebrities, and teenage mothers), and the popular culture that addresses these subjects. Melanie's work has been published in Celebrity Studies and Feminist Media Studies, and her monograph, Tweenhood: Femininity and Celebrity in Tween Popular Culture, is in press. She is the Book Reviews Editor of Celebrity Studies. E-mail: mjk29@leicester.ac.uk

\section{References}

Cleary, Belinda. 2018. "Fly High, Forever: Family, Friends and Schoolmates Say Goodbye to the Much-Loved Akubra Girl Amy 'Dolly' Everett, 14, Who Took Her Own Life after Being Tormented by Online Bullies.” Mail Online, 12 January. http://www.dailymail.co.uk/news/article-5261169/Amy-DollyEverett-laid-rest-funeral-service.html (accessed 16 January 2018).

Coulter, Natalie. 2014. Tweening the Girl: The Crystallization of the Tween Market. New York: Peter Lang. 
Driscoll, Catherine. 2002. Girls: Feminine Adolescence in Popular Culture and Cultural Theory. New York: Columbia University Press.

Harris, Anita. 2004. Future Girl: Young Women in the Twenty-first Century. New York: Routledge.

Kennedy, Melanie. 2018. in press. Tweenhood: Femininity and Celebrity in Tween Popular Culture. London: I.B. Tauris.

Pipher, Mary. 1994. Reviving Ophelia: Saving the Selves of Adolescent Girls. New York: Ballantine Books.

Vares, Tiina, and Sue Jackson. 2015. "Reading Celebrities/Narrating Selves:

'Tween' Girls, Miley Cyrus and the Good/Bad Girl Binary." Celebrity Studies 6 (4): 553-567. doi:10.1080/19392397.2015.1021822. 